\title{
Solvent Deuterium Oxide Isotope Effects on the Reactions of Organophosphorylated Acetylcholinesterase ${ }^{\dagger}$
}

\author{
Terrone L. Rosenberry \\ Mayo Clinic College of Medicine, Departments of Neuroscience and Pharmacology, Jacksonville, FL 32224, USA; \\ rosenberry@mayo.edu ; Tel.: +1-904-953-7375; Fax: +1-904-953-7370 \\ + This manuscript was given as an oral presentation on December 9, 2019 at the 16th Symposium on Cholinergic \\ Mechanisms in Rehovot, Israel.
}

Academic Editor: Zrinka Kovarik

Received: 1 August 2020; Accepted: 17 September 2020; Published: 25 September 2020

\begin{abstract}
Organophosphates (OPs) are esters of substituted phosphates, phosphonates or phosphoramidates that react with acetylcholinesterase (AChE) by initially transferring the organophosphityl group to a serine residue in the enzyme active site, concomitant with loss of an alcohol or halide leaving group. With substituted phosphates, this transfer is followed by relatively slow hydrolysis of the organophosphoryl AChE, or dephosphorylation, that is often accompanied by an aging reaction that renders the enzyme irreversibly inactivated. Aging is a dealkylation that converts the phosphate triester to a diester. OPs are very effective AChE inhibitors and have been developed as insecticides and chemical warfare agents. We examined three reactions of two organophosphoryl AChEs, dimethyl- and diethylphosphorylated AChE, by comparing rate constants and solvent deuterium oxide isotope effects for hydrolysis, aging and oxime reactivation with pralidoxime (2-PAM). Our study was motivated (1) by a published x-ray crystal structure of diethylphosphorylated $\mathrm{AChE}$, which showed severe distortion of the active site that was restored by the binding of pralidoxime, and (2) by published isotope effects for decarbamoylation that decreased from 2.8 for $\mathrm{N}$-monomethylcarbamoyl AChE to 1.1 for $\mathrm{N}, \mathrm{N}$-diethylcarbamoyl AChE. We previously reconciled these results by proposing a shift in the rate-limiting step from proton transfer for the small carbamoyl group to a likely conformational change in the distorted active site of the large carbamoyl enzyme. This proposal was tested but was not supported in this report. The smaller dimethylphosphoryl AChE and the larger diethylphosphoryl AChE gave similar isotope effects for both oxime reactivation and hydrolysis, and the isotope effect values of about two indicated that proton transfer was rate limiting for both reactions.
\end{abstract}

Keywords: acetylcholinesterase; paraoxon; dephosphorylation; reactivation; $\mathrm{D}_{2} \mathrm{O}$ isotope

\section{Introduction}

Acetylcholinesterase (AChE) catalyzes the hydrolysis of the neurotransmitter acetylcholine, and rapid hydrolysis of this ester is essential for normal cholinergic synaptic transmission. Acetylcholine hydrolysis proceeds by transfer of the acetyl group to the active site serine of AChE followed by hydrolysis, or deacetylation, of the acetyl enzyme, and both steps occur on a timescale of microseconds [1]. Other ester substrates of AChE proceed through a similar two-step catalytic pathway (Scheme 1). However, the pathways for the esters in Scheme 1 differ from that of acetylcholine in that these esters initially form a detectable reversible equilibrium complex with AChE with a dissociation constant, $K_{\mathrm{D}}$, before transfer of their carbamoyl or organophosphoryl groups (here referred to as acyl groups) to the active site serine to give carbamoyl or phosphoryl intermediates. This complex is an intermediate with acetylthiocholine but is not detectable, as explained in Equation (1) below. While the hydrolysis of the carbamoyl or organophosphoryl intermediates involves transfer of their 
acyl group from serine to water, their deacylation rate constants $\left(k_{3}\right.$ or $\left.k_{\mathrm{H}}\right)$ are orders of magnitude smaller than that of acetylated AChE [2,3]. Their slow deacylation makes them potent inhibitors of $\mathrm{AChE}$, and some carbamates and organophosphates (also denoted OPs) have been widely used as insecticides [4].

$$
\begin{gathered}
E+\mathrm{CX} \stackrel{K_{\mathrm{D}}}{\rightleftharpoons} E \mathrm{CX} \stackrel{k_{2}}{\longrightarrow} E \mathrm{C} \stackrel{k_{3}}{\longrightarrow} E+\mathrm{COH} \\
\mathrm{X} \\
E+\mathrm{OPX} \stackrel{K_{\mathrm{D}}}{\rightleftharpoons} E \mathrm{OPX} \stackrel{k_{2}}{\longrightarrow} E \mathrm{OP} \stackrel{k_{\mathrm{H}}}{\longrightarrow} E+\mathrm{POH} \\
+ \\
\mathrm{X}
\end{gathered}
$$

Scheme 1. Two-step catalytic pathway for carbamates (CX; [5,6]) and organophosphates (OPX; [7]).

Products are the alcohol leaving group $\mathrm{X}$ and the carbamic acid $(\mathrm{COH})$ or phosphate diester $(\mathrm{POH})$.

One noteworthy feature of $\mathrm{AChE}$ intermediates with carbamoyl and phosphoryl acyl groups (Figure 1) is that their relative deacylation rate constants $k_{3}$ or $k_{\mathrm{H}}$ decrease dramatically with an increase in acyl group size. This decrease may result in part from substantial distortion of the active site arising from the bulk of large acyl groups [8]. For example, an X-ray crystal structure of diethylphosphorylated hAChE generated from paraoxon [9] is shown in Figure 2A. In this structure, the diethylphosphoryl group is attached to Ser203. One ethoxy group faces Trp86 and the other faces Phe295, Phe297 and Phe338 in an acyl pocket. Hydrogen bonding within the catalytic triad (Ser203-His447-Glu334) remains intact but the adjacent acyl pocket residues and acyl loop (residue positions 280-297) are significantly perturbed relative to their positions in the ligand-free hAChE structure. Movements in residue backbone positions are necessary to avert steric clash, and the $C \alpha$ and the sidechain of Arg296 shift by $4.9 \mathrm{~A}^{\circ}$ and $14.9 \mathrm{~A}^{\circ}$, respectively. Large acyl loop backbone rearrangements have also been seen in mAChE and TcAChE inhibited by the OP diisopropylfluorophosphate [10,11]. However, stereoselective inhibition of $\mathrm{AChE}$ by OP nerve agents that place a smaller methyl group into the acyl pocket does not affect the acyl loop in the crystal structure in the same manner $[9,10,12]$.

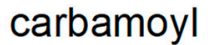<smiles>[Y9]COC(=O)N([R1])[R]</smiles>

$$
\begin{array}{cc}
\mathrm{R}_{1} & \mathrm{R}_{2} \\
\mathrm{CH}_{3} & \mathrm{H} \\
\mathrm{CH}_{3} & \mathrm{CH}_{3} \\
\mathrm{C}_{2} \mathrm{H}_{5} & \mathrm{CH}_{3} \\
\mathrm{C}_{2} \mathrm{H}_{5} & \mathrm{C}_{2} \mathrm{H}_{5}
\end{array}
$$

\section{phosphoryl}<smiles>[Z6][As]([R2])P([R2])([R])=O</smiles>

$$
\begin{array}{cc}
\mathrm{R}_{1} & \mathrm{R}_{2} \\
\mathrm{OCH}_{3} & \mathrm{OCH}_{3} \\
\mathrm{OC}_{2} \mathrm{H}_{5} & \mathrm{OC}_{2} \mathrm{H}_{5}
\end{array}
$$

Figure 1. Molecular structures of carbamoyl and phosphoryl groups attached to human acetylcholinesterase (AChE; squiggled line) compared in this report. Alkyl groups $\mathrm{R}_{1}$ and $\mathrm{R}_{2}$ are attached to the carbamoyl nitrogen atom and alkoxy groups $\mathrm{R}_{1}$ and $\mathrm{R}_{2}$ are attached to the phosphoryl phosphorus atom. 
These shifts in the acyl pocket residues and acyl loop in diethylphosphorylated hAChE can be largely reversed by cationic ligand binding to the active site [9]. The interaction of cationic oximes with organophosphorylated AChEs is of intense interest because oximes have been shown to reactivate these AChEs by displacing the serine hydroxyl and releasing the organophosphorylated oxime [7,13]. The structure in which $50 \mathrm{mM}$ 2-PAM was diffused into the crystals to form a complex of diethylphosphorylated hAChE with the cationic oxime 2-PAM reveals two bound 2-PAM molecules (Figure 2B), one in the peripheral site and the other stacked against the sidechain of Trp86. In this ternary complex, the backbone conformation of the acyl loop resembles that of the ligand-free state and appears to be stabilized by oxime binding. Therefore, diffusion of these oximes into the crystals of diethylphosphorylated $\mathrm{hAChE}$ promoted a restoration of the acyl pocket residues and acyl loop to their locations in the unmodified hAChE structure.

A
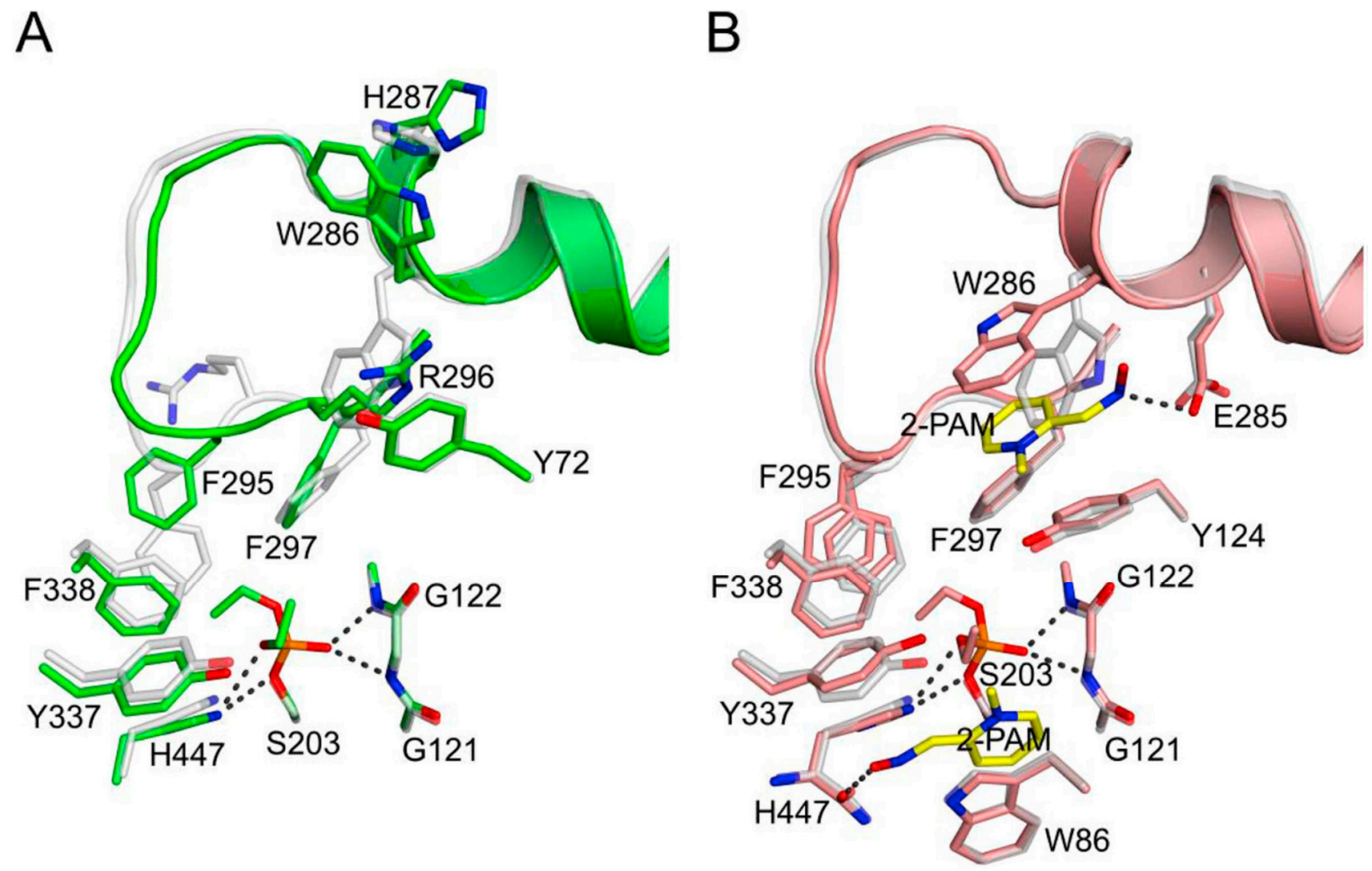

Figure 2. Conformational changes in hAChE induced by paraoxon inhibition [9]. Structural perturbations seen in diethylphosphorylated hAChE without (A) and with bound 2-PAM (B) are visualized by superimposition with ligand-free hAChE. Carbon atoms of the oximes are colored yellow, and carbon atoms of protein residues are colored by complex: green in (A) and salmon in (B); and ligand-free hAChE, semitransparent gray. Nitrogen, oxygen, and phosphorus atoms are colored dark blue, red and orange, respectively. Residues of the helix preceding the acyl loop and of the acyl loop up to position 298 are drawn as ribbons. Atoms of select residues, reactivators and phosphate adducts are drawn as sticks and hydrogen bonds are depicted by dashed gray lines.

The catalytic effects of active site distortion in diethylphosphorylated AChE on the deacylation pathway can be examined by determining $\mathrm{D}_{2} \mathrm{O}$ isotope effects on the deacylation reactions. Here we investigate the reaction rate constants and $\mathrm{D}_{2} \mathrm{O}$ isotope effects for three reactions of diethylphosphorylated $\mathrm{AChE}$, which shows crystallographic evidence of active site distortion, and of dimethylphosphorylated AChE, which does not [9,10,12]. 


\section{Results}

The primary objectives of this paper are to obtain the solvent $\mathrm{D}_{2} \mathrm{O}$ isotope effects for three of four reactions that involve organophosphorylated AChEs. The four reactions are outlined in Scheme 2, and the isotope effects are shown in Table 1 below. Because the determination of solvent $\mathrm{D}_{2} \mathrm{O}$ isotope effects requires accuracy and precision, an emphasis is placed on protocols for rate constant measurement. The isotope effects obtained are then compared to those previously measured for carbamoylated AChEs, and differences among them are interpreted in the context of X-ray crystal structures determined for organophosphorylated AChEs like those shown in Figure 2.

a) Denaturation

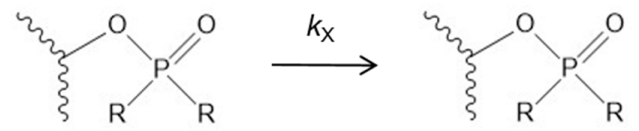

b) Aging<smiles>[Y]C(C)OP([R])([R])=O</smiles>

c) Hydrolysis<smiles></smiles><smiles>CCCC(C)O</smiles><smiles>[R]P([R])(=O)O</smiles>

d) Oxime Reactivation<smiles>[R12]CC</smiles><smiles>CC(C)O</smiles><smiles>[R]P([R])(=O)O[Na]</smiles>

Scheme 2. Four reactions of organophosphorylated AChE (a-d). The alcohol RH, the phosphate diester $\mathrm{R}_{2} \mathrm{P}(\mathrm{O}) \mathrm{OH}$, and the phosphate triester $\mathrm{R}_{2}$ (oxime) $\mathrm{P}(\mathrm{O})$ are the products released during the aging, hydrolysis and reactivation reactions, respectively.

Protocols to measure the rate constants of the reactions of organophosphorylated AChEs in Scheme 2, in both $\mathrm{H}_{2} \mathrm{O}$ and $\mathrm{D}_{2} \mathrm{O}$, are outlined in the Materials and Methods, and representative reactions are illustrated in Figures 3-5 below.

\subsection{Denaturation Rate Constants $k_{X}$ for Organophosphorylated AChE}

Before the rate constants for reactions $b, c$ and $d$ in Scheme 2 can be determined, the loss of AChE activity arising from enzyme denaturation must be taken into consideration. The reaction denoted denaturation in Scheme 2a was detected with control AChE and with fully reactivated AChE in the absence of OPs. Bovine serum albumen (BSA) was added to the assay solution to stabilize the AChE, but the enzyme still showed a slow loss of activity with a rate constant $k_{\mathrm{X}}$ that (1) in some cases was close enough to the aging rate constant $k_{\mathrm{A}}$ and the hydrolysis rate constant $k_{\mathrm{H}}$ to require inclusion in the analytical equations and (2) was stabilized by 2-PAM and thus depended on the concentration of 2-PAM. Individual measurements of $k_{X}$ ranged from $2-7 \times 10^{-5} \mathrm{~min}^{-1}$ and are illustrated in Figures 4 and 5A below. The same denaturation constant $k_{X}$ was assumed to apply to free and organophosphorylated AChE. 


\subsection{Aging Rate Constants $k_{A}$ for Organophosphorylated AChE}

The fact that organophosphorylated AChE can undergo multiple reactions (Scheme 2) required a sequential approach to obtaining the rate constants for these reactions. Fitting some of the data here to equations required preliminary estimates of some rate constants that were refined in the fitting of later data. The aging reaction in Scheme $2 b$ is the loss of an alkoxy group attached to the phosphorus atom [14]. The resulting phosphate diester that remains covalently linked to AChE is an extremely stable inactive enzyme form that cannot be reactivated by oxime (Figure 3). The protocol we used to measure the aging rate constants $k_{\mathrm{A}}$ is indicated in the Figure 3 legend. We followed this protocol to obtain our best estimates of $k_{\mathrm{A}}$ in both $\mathrm{H}_{2} \mathrm{O}$ and $\mathrm{D}_{2} \mathrm{O}$. AChE was maintained in a fully organophosphorylated form for various times $t_{\text {aged, }}$ after which it was diluted into a high concentration of 2-PAM to rapidly reactivate all of the enzyme that had not been aged. Figure 3A demonstrates that, with reasonable initial estimates of $k_{\mathrm{X}}, k_{\mathrm{A}}, k_{\mathrm{H}}$, and $k_{\mathrm{r}}, 2$-PAM reactivation proceeds rapidly. Fitting confirmed that all values of $v$ measured after the initial value near $t=0$ essentially corresponded to the final value of $v$, denoted $v_{\mathrm{F}}$. Plots of these $v_{\mathrm{F}}$ against $t_{\text {aged }}$ could be analyzed with Equation (3) as shown in Figure 3B to give values of $k_{\mathrm{A}}$ presented in Table 1.

Min aged before 2-PAM addition

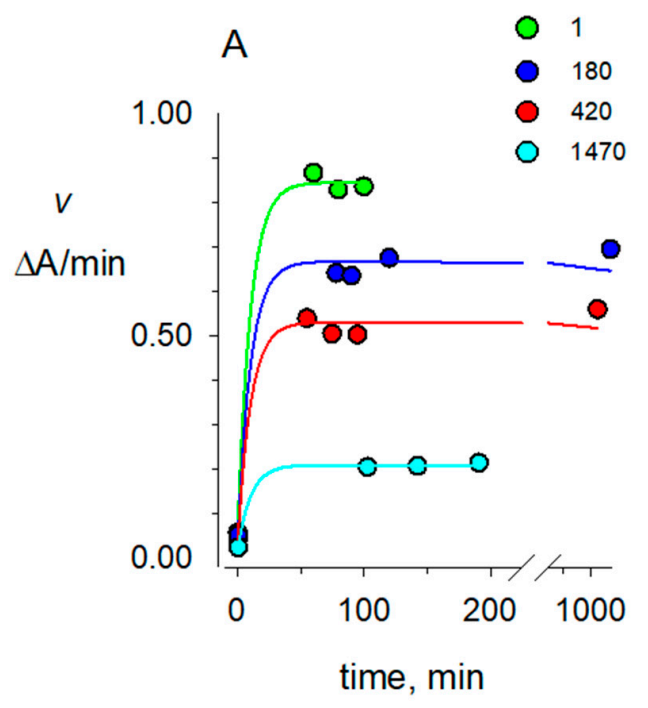

$v_{\mathrm{F}}$ compiled from panel $\mathrm{A}$

B

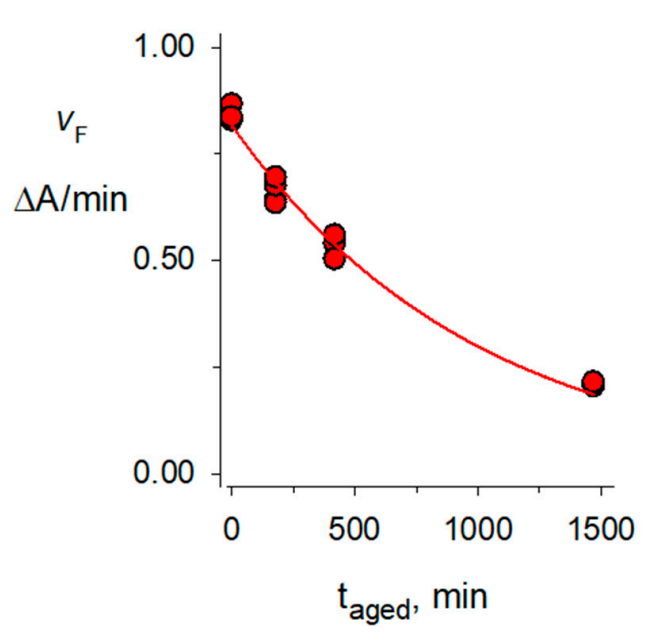

Figure 3. Aging of dimethylphosphorylated AChE in $\mathrm{H}_{2} \mathrm{O}$. A mixture of $2.4 \mu \mathrm{M}$ paraoxon methyl (OP) and $0.5 \mu \mathrm{M}$ AChE in $100 \mathrm{mM}$ sodium phosphate and 0.1\% BSA ( $\mathrm{pH} 8.0$ ) was incubated for $60 \mathrm{~min}$ at $25^{\circ} \mathrm{C}$. The incubation was then aged for the various times indicated before addition of 2-PAM, with the earliest addition of 2-PAM designated as $t_{\text {aged }}=0$. To ensure that the OP remained in excess during aging, additional OP was added $\left(1.7 \mu \mathrm{M}\right.$ at $t_{\text {aged }} 5$ and $185 \mathrm{~min}$ and $3.6 \mu \mathrm{M}$ at $\left.t_{\text {aged }} 425 \mathrm{~min}\right)$. At the indicated $t_{\text {aged }}$ of 1, 180, 420 and $1470 \mathrm{~min}$, portions of the aged reaction were diluted 24-fold into $1.0 \mathrm{mM}$ 2-PAM. (A) Aliquots $(30 \mu \mathrm{L})$ of each dilution were assayed as indicated in the Materials and Methods at the times indicated on the $x$-axis. Assay values $v$ were fit to Equation (2), with the indicated $t_{\text {aged }}$ fixed. Fixed initial estimates ( $\mathrm{min}^{-1}$ for $k$ values) of $k_{\mathrm{X}}=2.5 \times 10^{-5}, k_{\mathrm{H}}=6.5 \times 10^{-3}, k_{\mathrm{r}}=9 \times 10^{-2}$ and $k_{\mathrm{A}}=2 \times 10^{-3}$ gave fitted $E_{\mathrm{tot}}=0.86 \Delta \mathrm{A} / \mathrm{min}$ (green line); this $E_{\mathrm{tot}}$ was then fixed along with the same values of $k_{\mathrm{X}}, k_{\mathrm{H}}$, and $k_{\mathrm{r}}$ to fit $k_{\mathrm{A}}=1-2 \times 10^{-3}$ and $E_{0}=0.01-0.02 \Delta \mathrm{A} / \mathrm{min}$ (blue, red, and cyan lines). Values for times after the initial time point were observed to correspond to the final value of $v$, denoted $v_{\mathrm{F}}$, in this equation. (B) Assay values corresponding to $v_{\mathrm{F}}$ in panel A were analyzed with Equation (3) with a fixed $k_{\mathrm{X}}=2.5 \times 10^{-5} \mathrm{~min}^{-1}$ to give $E_{\text {tot }}=0.82 \Delta \mathrm{A} / \mathrm{min}$ and a $k_{\mathrm{A}}$ value of $(980+60) \times 10^{-6} \mathrm{~min}^{-1}$ included in Table 1. 


\subsection{Hydrolysis Rate Constants $k_{H}$ for Organophosphorylated AChE}

The hydrolysis rate constants $k_{\mathrm{H}}$ were measured in $\mathrm{H}_{2} \mathrm{O}$ and $\mathrm{D}_{2} \mathrm{O}$ with the protocol in the Figure 4 legend. AChE was organophosphorylated and diluted with or without $200 \mu \mathrm{M} 2$-PAM. Assay values $v$ from the dilution with 2-PAM rapidly reached maximums and were analyzed with Equation (2) to determine $E_{\text {tot }}$. This value of $E_{\text {tot }}$ was then fixed in Equation (2) to fit the values of $v$ from the dilution without 2-PAM to obtain $k_{\mathrm{H}}$ (Figure 4 ).

In contrast to the protocol for the aging reaction in Figure 3A, where a slight excess of OP during preincubation was rapidly turned over by dilution into a high concentration of 2-PAM, the hydrolysis reaction was defined in the absence of 2-PAM and its time course was sensitive to any excess of OP. An excess was indicated by an $E_{0}$ close to zero and by a lag in the increase in $v$ with time. Centrifugation through a spin column was employed to minimize unreacted OP but, in addition, the stoichiometry of AChE and OP was set close to one and the incubation time was limited to insure that, in most cases, $E_{0}$ was significantly greater than zero. However, this was not the case in Figure 4 , where $E_{0}$ approached zero.

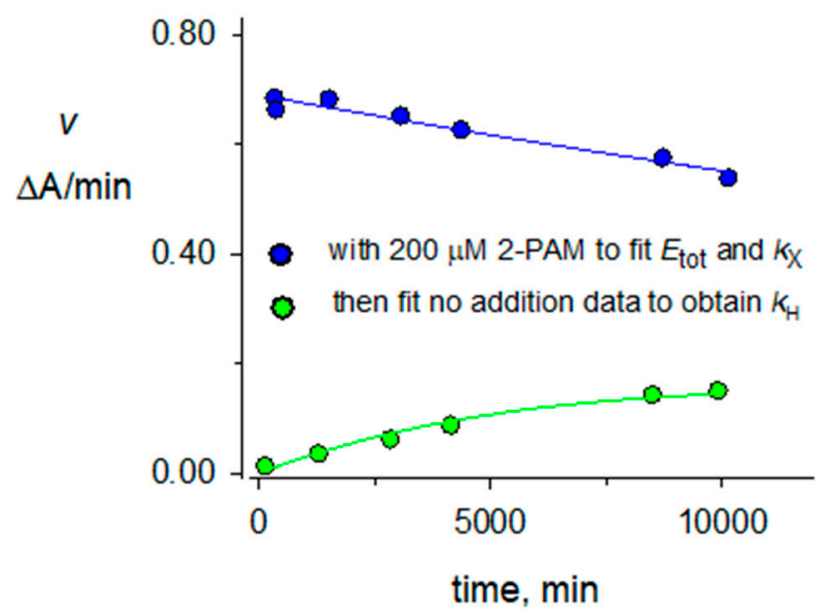

Figure 4. Denaturation and hydrolysis of diethylphosphorylated AChE in $\mathrm{D}_{2} \mathrm{O}$. A mixture of $2.0 \mu \mathrm{M}$ paraoxon and $1.4 \mu \mathrm{M}$ AChE in $100 \mathrm{mM}$ sodium phosphate and $0.1 \% \mathrm{BSA}$ (buffer) in $\mathrm{D}_{2} \mathrm{O}(\mathrm{pH}$ 8.0) was incubated for $70 \mathrm{~min}$ at $25^{\circ} \mathrm{C}$. A 4 -fold excess of buffer in $\mathrm{D}_{2} \mathrm{O}$ was added, and $200 \mu \mathrm{L}$ was applied to a $0.5 \mathrm{~mL}$ Sephadex G50 spin column (Fisher) that had been prewashed four times in buffer in $\mathrm{D}_{2} \mathrm{O}$ and centrifuged at $1000 \times g$ for $1 \mathrm{~min}$. The eluent was cooled to $4{ }^{\circ} \mathrm{C}$, and $60 \mu \mathrm{L}$ was added either to $640 \mu \mathrm{L}$ of buffer in $\mathrm{D}_{2} \mathrm{O}$ at $25^{\circ} \mathrm{C}$ or $640 \mu \mathrm{L}$ of the same buffer with 2-PAM (to $200 \mu \mathrm{M}$ ) at $25^{\circ} \mathrm{C}$. Aliquots $(30 \mu \mathrm{L})$ were assayed as in Figure 3 at the times indicated on the $x$-axis. Assay values $v$ for the solution containing 2-PAM (blue points that correspond to enzyme denaturation) were first fit to Equation (2) with $t_{\text {aged }}$ set to 0 and fixed initial estimates $\left(\mathrm{min}^{-1}\right.$ for $k$ values) of $k_{\mathrm{A}}=4 \times 10^{-5}$, $k_{\mathrm{H}}=4 \times 10^{-5}, k_{\mathrm{r}}=2 \times 10^{-2}$ and $E_{0}=0.01 \Delta \mathrm{A} / \mathrm{min}$ to obtain $k_{\mathrm{X}}=2.2 \times 10^{-5}$ and $E_{\mathrm{tot}}=0.69 \Delta \mathrm{A} / \mathrm{min}$. These values of $t_{\mathrm{aged}}, k_{\mathrm{A}}$, and $E_{\mathrm{tot}}$ along with $k_{\mathrm{X}}=4 \times 10^{-5}$ and $k_{\mathrm{r}}=0$ were then fixed into Equation (2) to fit the assay values $v$ for the solution without 2-PAM (green points that reflect enzyme denaturation and diethylphosphorylated enzyme hydrolysis). This fitting gave $E_{0}=0.003 \Delta \mathrm{A} / \mathrm{min}$ and a $k_{\mathrm{H}}$ value of $(47+3) \times 10^{-6} \mathrm{~min}^{-1}$ included in Table 1 .

\subsection{2-PAM Reactivation Rate Constants $k_{R}$ for Organophosphorylated AChE}

The reactivation rate constants $k_{\mathrm{r}}$ depend on the concentration of 2-PAM, but at the 2-PAM concentrations employed here they were considerably larger than rate constants for denaturation, aging and hydrolysis described above. Nevertheless, the determination of accurate solvent $\mathrm{D}_{2} \mathrm{O}$ isotope effects required inclusion of these smaller rate constants in Equation (2). The protocol for obtaining values of $k_{\mathrm{r}}$ is shown in Figure 5A. A rapid increase in assay values $v$ was observed on adding organophosphorylated AChE to 2-PAM, followed by a much slower decrease in $v$ that we 
attributed to enzyme denaturation. The much longer slow decrease dominated the fitting procedure when the entire time course was analyzed, so fitting was divided into two steps. In the first step only the denaturation rate constant $k_{\mathrm{X}}$ was retained, and it showed a clear decrease in value at higher 2-PAM concentrations (Figure 5A) as noted above. The second fitting step retained the value of $k_{X}$ from the first step as an additional fixed variable, and $k_{\mathrm{r}}$ was fitted from the initial increase in $v$ (Figure 5A). Values of $k_{\mathrm{r}}$ obtained at different 2-PAM concentrations were then analyzed according to Equation (4) to obtain the maximum reactivation rate constant $k_{\mathrm{R}}$ at concentrations of 2-PAM that saturated the organophosphorylated enzyme (Figure 5B).

A

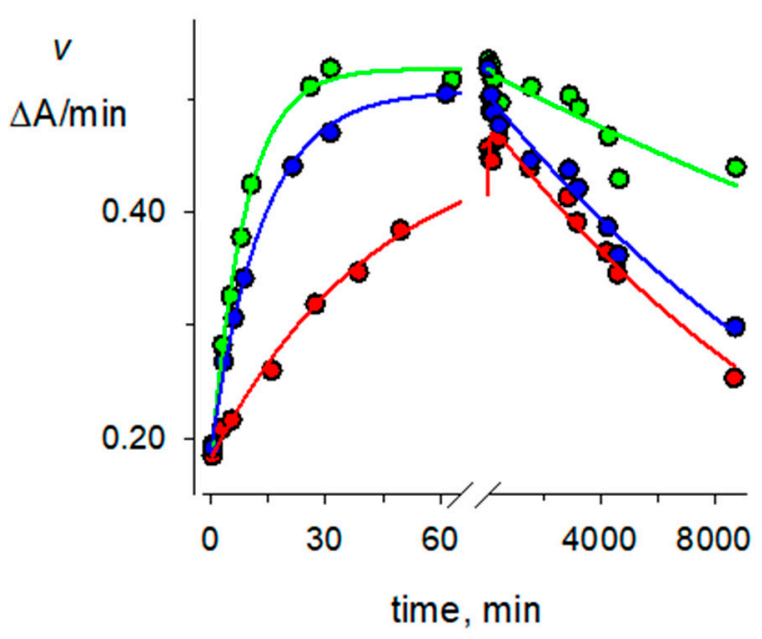

B

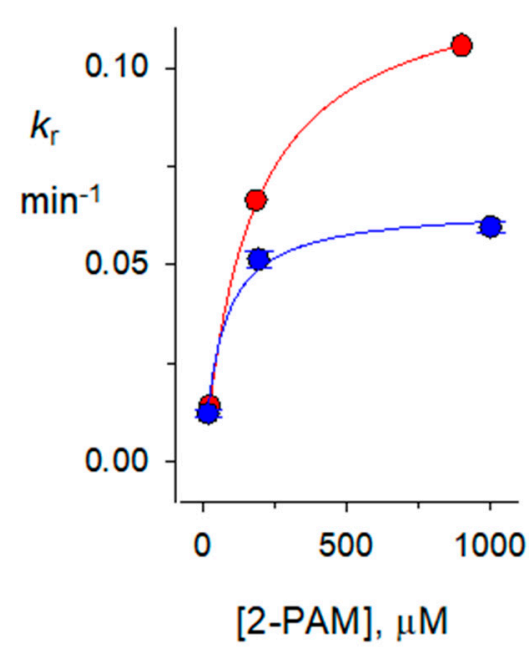

Figure 5. 2-PAM reactivation of dimethylphosphorylated $\mathrm{AChE}$ in $\mathrm{H}_{2} \mathrm{O}$. A mixture of $1.6 \mu \mathrm{M}$ paraoxon methyl and $1.5 \mu \mathrm{M}$ AChE in $100 \mathrm{mM}$ sodium phosphate and $0.1 \%$ BSA (buffer) in $\mathrm{H}_{2} \mathrm{O}$ ( $\mathrm{pH}$ 8.0) was incubated for $30 \mathrm{~min}$ at $25^{\circ} \mathrm{C}$. A 2.5 -fold excess of buffer in $\mathrm{H}_{2} \mathrm{O}$ was added, and $100 \mu \mathrm{L}$ was applied to a $0.5 \mathrm{~mL}$ spin column that had been prewashed four times in buffer in $\mathrm{H}_{2} \mathrm{O}$ and centrifuged at $1000 \times g$ for $1 \mathrm{~min}$. The eluent was added to $215 \mu \mathrm{L}$ of buffer in $\mathrm{H}_{2} \mathrm{O}$ and cooled to $4{ }^{\circ} \mathrm{C}$, and $100 \mu \mathrm{L}$ aliquots were added at time zero to $700 \mu \mathrm{L}$ of buffer in $\mathrm{H}_{2} \mathrm{O}$ containing final concentrations of 905,185 , or $24 \mu \mathrm{M}$ 2-PAM at $25^{\circ} \mathrm{C}$. (A) Aliquots $(30 \mu \mathrm{L})$ were assayed as indicated in Figure 3 at the times indicated on the $x$-axis. Assay values $v$ for the solutions containing $905 \mu \mathrm{M}$ (green points), $185 \mu \mathrm{M}$ (blue points) or $24 \mu \mathrm{M}$ 2-PAM (red points) were analyzed with Equation (2) in two steps, with $t_{\text {aged }}$ set to 0 and $k_{\mathrm{A}}$ and $k_{\mathrm{H}}$ fixed at $2 \times 10^{-3} \mathrm{~min}^{-1}$ and $6 \times 10^{-3} \mathrm{~min}^{-1}$, respectively, and $k_{\mathrm{r}}, k_{\mathrm{X}}, E_{\text {tot }}$, and $E_{0}$ as fitted variables. In the first step, points over the entire 8800-min time course were fitted to obtain $k_{\mathrm{X}}\left(\mathrm{in} \min ^{-1}\right.$ ) $=2.5 \times 10^{-5}$ (green points), $6.3 \times 10^{-5}$ (blue points), and $7.0 \times 10^{-5}$ (red points). These $k_{X}$ were then fixed along with $k_{\mathrm{A}}$ and $k_{\mathrm{H}}$ in the second step in which time courses of 250 to $450 \mathrm{~min}$ were fitted to give more precise values of $k_{\mathrm{r}}$. (B) Values of $k_{\mathrm{r}}$ from the second fitting step in panel A were then fitted to Equation (4) to obtain values of $k_{\mathrm{R}}(12.5+0.2) \times 10^{-2} \mathrm{~min}^{-1}$ included in Table 1 . The corresponding fit of $k_{\mathrm{r}}$ values obtained in $\mathrm{D}_{2} \mathrm{O}$ is also shown. Fitted values of $K_{\mathrm{P}}$ were $170 \mu \mathrm{M}$ in $\mathrm{H}_{2} \mathrm{O}$ and $90 \mu \mathrm{M}$ in $\mathrm{D}_{2} \mathrm{O}$. Error values typical of $k_{\mathrm{r}}$ for both $\mathrm{H}_{2} \mathrm{O}$ and $\mathrm{D}_{2} \mathrm{O}$ data sets are shown with the $\mathrm{D}_{2} \mathrm{O}$ data points.

\subsection{Accuracy of Rate Constants for Reactions of Organophosphorylated hAChE}

In addition to the rate constants given in Table 1 , we also determined $k_{X}$ values in the absence of 2-PAM in $\mathrm{H}_{2} \mathrm{O}\left((53 \pm 7) \times 10^{-6} \mathrm{~min}^{-1}, n=7\right)$ and in $\left.\mathrm{D}_{2} \mathrm{O}(41 \pm 14) \times 10^{-6} \mathrm{~min}^{-1}, n=3\right)$. These values are significant because, in some cases, several measured rate constants are close in value, rendering the accuracy of one rate constant highly dependent upon another. For example, values of $k_{\mathrm{H}}, k_{\mathrm{A}}$ and $k_{\mathrm{X}}$ for diethylphosphorylated $\mathrm{AChE}$ are almost identical in $\mathrm{D}_{2} \mathrm{O}$. The rate constants most sensitive to these equivalencies are the $k_{\mathrm{A}}$ values in Table 1. These values were obtained by fitting Equation (3), where the exponential rate constant is $k_{\mathrm{A}}+k_{\mathrm{X}}$. Therefore, from the $40 \times 10^{-6} \mathrm{~min}^{-1}$ value of $k_{\mathrm{A}}$ in 
Table 1, a 2-fold increase in $k_{\mathrm{X}}$ renders $k_{\mathrm{A}}$ close to zero. The value of $k_{\mathrm{X}}$ also plays an important, although lesser, role in the determination of $k_{\mathrm{H}}$ for diethylphosphorylated AChE in $\mathrm{D}_{2} \mathrm{O}$ (Table 1 and Figure 4): a 2-fold increase in the fixed value of $k_{\mathrm{X}}$ in Equation (2) increases $k_{\mathrm{H}}$ by $45 \%$, whereas a 2-fold decrease in $k_{\mathrm{X}}$ decreases $k_{\mathrm{H}}$ by $20 \%$. Values of $k_{\mathrm{H}}, k_{\mathrm{A}}$, and $k_{\mathrm{X}}$ for dimethylphosphorylated AChE diverge to a much greater extent (see Table 1), making their accuracy largely independent of each other. In view of these differences in the rate constant interdependence of $k_{\mathrm{A}}$ and $k_{\mathrm{H}}$, the similarities in the solvent $\mathrm{D}_{2} \mathrm{O}$ isotope effects for dimethyl- and diethylphosphorylated AChE in Table 1 are reassuring but possibly serendipitous.

Table 1. Rate constants for reactions of organophosphorylated $A C h E$ and their solvent $\mathrm{D}_{2} \mathrm{O}$ isotope effects.

\begin{tabular}{|c|c|c|c|c|c|}
\hline Phosphoryl Substituents & Reaction & $k\left(10^{-6} \mathrm{~min}^{-1}\right) \mathrm{H}_{2} \mathrm{O}^{a}$ & $k\left(10^{-6} \min ^{-1}\right) \mathrm{D}_{2} \mathrm{O}$ & $n$ & $k \mathrm{H}_{2} \mathrm{O} / k \mathrm{DO}^{b}$ \\
\hline \multirow{2}{*}{$\begin{array}{l}\text { Dimethyl- } \\
\text { Diethyl- }\end{array}$} & \multirow{2}{*}{ Aging $\left(k_{\mathrm{A}}\right)$} & $1500 \pm 500$ & $1400 \pm 500$ & 2 & $1.1 \pm 0.1$ \\
\hline & & $39 \pm 7^{c}$ & $41 \pm 4^{c}$ & 1 & $1.0 \pm 0.2$ \\
\hline \multirow{2}{*}{$\begin{array}{l}\text { Dimethyl- } \\
\text { Diethyl- }\end{array}$} & \multirow{2}{*}{ Hydrolysis $\left(k_{\mathrm{H}}\right)$} & $6000 \pm 530$ & $3100 \pm 360$ & 2 & $1.9 \pm 0.1$ \\
\hline & & $83 \pm 12$ & $41 \pm 5$ & 3 & $2.0 \pm 0.1$ \\
\hline \multirow{2}{*}{$\begin{array}{l}\text { Dimethyl- } \\
\text { Diethyl- }\end{array}$} & \multirow{2}{*}{ 2-PAM reactivation $\left(k_{\mathrm{R}}\right)$} & $120,000 \pm 6000$ & $61,000 \pm 4000$ & 2 & $1.96 \pm 0.04$ \\
\hline & & $23,000 \pm 1500$ & $15,000 \pm 300$ & 2 & $1.68 \pm 0.14$ \\
\hline
\end{tabular}

${ }^{a}$ Values listed for rate constants $k$ in $\mathrm{H}_{2} \mathrm{O}$ are means of $n$ experiments with the standard error of the mean. Since each entry in this table included paired measurements in $\mathrm{H}_{2} \mathrm{O}$ and $\mathrm{D}_{2} \mathrm{O}, n$ values were always the same for both solvents.

$b$ The solvent $\mathrm{D}_{2} \mathrm{O}$ isotope effect was the ratio of a rate constant in $\mathrm{H}_{2} \mathrm{O}$ to that in $\mathrm{D}_{2} \mathrm{O}$. It was the unweighted average of the isotope effects from the $n$ experiments calculated individually for paired $\mathrm{H}_{2} \mathrm{O}_{\text {and }} \mathrm{D}_{2} \mathrm{O}$ reactions in each experiment. When $n=1$, the standard error was determined from the combined errors of the $\mathrm{H}_{2} \mathrm{O}_{\text {and }} \mathrm{D}_{2} \mathrm{O}$ fits to Equation (3). ${ }^{c}$ When $n=1$, the standard error was determined from the error of the fit to Equation (3). However, the overall errors in $k_{\mathrm{A}}$ for diethylphosphorylated AChE depend much more on the values of $k_{\mathrm{X}}$ and $k_{\mathrm{H}}$ than on replicate values of $k_{\mathrm{A}}$ (see Section 2.5), and therefore replicate values of $k_{\mathrm{A}}$ for these species were not made.

\subsection{Solvent Deuterium Oxide Isotope Effects on Reaction Rate Constants}

Analyses of isotope effects in $\mathrm{D}_{2} \mathrm{O}$ relative to $\mathrm{H}_{2} \mathrm{O}$ have been useful in clarifying details of the AChE reaction pathway with a variety of substrates [15,16], but we've found few reports of these isotope effects on the reactions of phosphorylated AChE. In our experiments in this report, we paired rate constant determinations in $\mathrm{H}_{2} \mathrm{O}$ and $\mathrm{D}_{2} \mathrm{O}$ by running them on the same day, starting with the same stock AChE frozen aliquot and employing the same dilution sequence. Our results are presented in Table 1, and they are examined in detail in the Discussion.

\section{Discussion}

\subsection{Kinetics of Decarbamoylation and of the Hydrolysis of Organophosphorylated AChE}

Rate constants for organophosphorylated AChE in Table 1 are in reasonable agreement with corresponding values previously reported in slightly different solvents, $\mathrm{pH}$ conditions and temperatures. Values of $k_{\mathrm{A}}=3000 \times 10^{-6} \mathrm{~min}^{-1}$, of $k_{\mathrm{H}}=17,000 \times 10^{-6} \mathrm{~min}^{-1}$, and of $k_{\mathrm{R}}=480,000 \times 10^{-6} \mathrm{~min}^{-1}$ were obtained for dimethylphosphorylated human AChE [17]. For diethylphosphorylated AChE, values of $k_{\mathrm{A}}=170 \times 10^{-6} \mathrm{~min}^{-1}$ and of $k_{\mathrm{H}}=120 \times 10^{-6} \mathrm{~min}^{-1}$ were obtained with the mouse enzyme [18] and of $k_{\mathrm{R}}=60,000 \times 10^{-6} \mathrm{~min}^{-1}$ for the human enzyme [19].

An increase in size of the carbamoyl or organophosphoryl group attached to AChE significantly reduced the value of $k_{3}$ or $k_{\mathrm{H}}$ for deacylation. In Table 1 , the $k_{\mathrm{H}}$ for diethylphosphorylated AChE is about 75-fold lower than that for dimethylphosphorylated AChE. A similar trend was seen with carbamoylated AChE, where $k_{3}$ for $N, N$-diethylcarbamoyl AChE was about 300-fold lower than that for $\mathrm{N}, \mathrm{N}$-dimethylcarbamoyl AChE [2]. The difference for the organophosphorylated AChEs may result from distortion of the AChE active site by the larger diethylphosphoryl group as seen in Figure 2A. The organophosphoryl group size appears less important for oxime reactivation, as $k_{R}$ in Table 1 for 2-PAM reactivation of diethylphosphorylated AChE is only 5-fold lower than that for 
dimethylphosphorylated AChE. To address the consequences of active site distortion more directly, we analyzed the solvent $\mathrm{D}_{2} \mathrm{O}$ isotope effects in the following section.

\subsection{Solvent Deuterium Oxide Isotope Effects on Rate Constants for Reactions of Organophosphorylated AChE}

When proton transfer occurs in the rate-limiting step of a reaction, the rate constant for that reaction shows a solvent $\mathrm{D}_{2} \mathrm{O}$ isotope effect. Rate-limiting proton transfer in an acylation or deacylation reaction results in a rate constant decrease of 2 to 3-fold when $\mathrm{D}_{2} \mathrm{O}$ replaces $\mathrm{H}_{2} \mathrm{O}$ as the solvent [20]. AChE-catalyzed acetylcholine hydrolysis falls well within this range, as $k_{\text {cat }}$ (a combination of acylation and deacylation rate constants) has a solvent $\mathrm{D}_{2} \mathrm{O}$ isotope effect of $2.4[15,21]$. However, the isotope effect drops from 2.4 for $k_{\text {cat }}$ to 1.1-1.2 for the second order hydrolysis rate constant $k_{\text {cat }} / K_{\text {app }}$ (also denoted $k_{\mathrm{E}}$ ) with good substrates of $\mathrm{AChE}$ like acetylcholine. To interpret this drop, we proposed that proton transfer in the acylation step $k_{2}$ was rate-limiting for $k_{\text {cat }}$ but that an earlier step like substrate binding, or an induced-fit conformational change that does not involve proton transfer, was rate-limiting for the second order rate constant $k_{\text {cat }} / K_{\text {app }}$ [15]. More explicitly, the solvent $\mathrm{D}_{2} \mathrm{O}$ isotope effect is determined by the commitment to catalysis, denoted C [16]. In the very simple case of Scheme 3 and Equation (1), acetylcholine (S) binds to enzyme $E$ with an association rate constant of $k_{\mathrm{S}}$ and a dissociation rate constant of $k_{-S}$ to give an $E S$ complex.

$$
E+\mathrm{S} \underset{k_{-\mathrm{S}}}{\stackrel{k_{\mathrm{S}}}{\rightleftharpoons}} E \mathrm{~S} \stackrel{k_{2}}{\longrightarrow} \mathrm{P}
$$

Scheme 3. Pathway for hydrolysis of acetylthiocholine (S) by AChE (E).

Subsequent acylation with a rate constant $k_{2}$ gives an acyl enzyme and choline products, here just denoted P. The observed rate constant $k_{\mathrm{E}}$ is given by Equation (1). The acylation step $k_{2}$ involves proton transfer and has an isotope effect of 2-3, while $k_{S}$ and $k_{-S}$ are assumed not to involve proton transfer. The commitment to catalysis is defined as $\mathrm{C}=k_{2} / k_{-\mathrm{S}}$. When $\mathrm{C}$ is small, $k_{\mathrm{E}}=k_{\mathrm{S}} k_{2} / k_{-\mathrm{S}}$, and $k_{\mathrm{E}}$ shows an isotope effect. When $C$ is large, $k_{\mathrm{E}}=k_{\mathrm{S}}$ and it does not.

$$
k_{\mathrm{E}}=\frac{k_{\mathrm{S}} k_{2}}{\left(k_{-\mathrm{S}}+k_{2}\right)}
$$

A comparable interpretation may be applied to the aging reaction in Scheme 2. This reaction is enzyme catalyzed [22] and involves loss of an alkyl group as the organophosphoryl adduct is converted from a phosphate triester to a diester. While a proton is transferred to the alkyl leaving group in this reaction, this transfer does not appear to be rate limiting as the solvent $\mathrm{D}_{2} \mathrm{O}$ isotope effects for the aging reaction rate constant $k_{\mathrm{A}}$ in Table 1 are about 1.0. We have found no other reports of isotope effects on aging of dimethyl- or diethylphosphorylated AChE, but a similar isotope effect of 1.2 has been reported for aging of 2-propoxy-methylphosphonylated AChE [23].

We next asked whether the hydrolysis and oxime reactivation reactions in Scheme 2 involve general acid-base catalysis with rate-limiting proton transfer. To facilitate the analysis, we consider Scheme 4, which shows a slight extension of Scheme 1 in which a second acyl enzyme species is added in conformational equilibrium with the first. In particular, Scheme 4 includes an inactive enzyme form $\left(E_{1} \mathrm{C}\right.$ or $\left.E_{1} \mathrm{OP}\right)$ with a distorted active site and an active enzyme form $\left(E_{2} \mathrm{C}\right.$ or $\left.E_{2} \mathrm{OP}\right)$ that can undergo hydrolysis with a rate constant $k_{3}$ or $k_{\mathrm{H}}$. The forward and reverse rate constants for these equilibria are $k_{\mathrm{F}}$ and $k_{-\mathrm{F}}$, respectively, and they are assumed not to involve proton transfer. The general solution to Scheme 4 is more complicated than that of Scheme 3, as neither $E_{2} \mathrm{C}$ nor $E_{2} \mathrm{OP}$ necessarily is in the steady state. However, two extreme cases may be considered in which these intermediates are in the steady state: (1) the commitment to catalysis $k_{3} / k_{-\mathrm{F}}$ or $k_{\mathrm{H}} / k_{-\mathrm{F}}$ is small, and the deacylation rate constant $k_{3} k_{\mathrm{F}} /\left(k_{-\mathrm{F}}+k_{3}\right)$ or $k_{\mathrm{H}} k_{\mathrm{F}} /\left(k_{-\mathrm{F}}+k_{\mathrm{H}}\right)$ shows the solvent $\mathrm{D}_{2} \mathrm{O}$ isotope effect inherent in $k_{3}$ or $k_{\mathrm{H}}$; (2) the commitment to catalysis $k_{3} / k_{-\mathrm{F}}$ or $k_{\mathrm{H}} / k_{-\mathrm{F}}$ is large, the acyl intermediates are not equilibrated and 
the deacylation rate constant $k_{3} k_{\mathrm{F}} /\left(k_{-\mathrm{F}}+k_{\mathrm{H}}\right)$ or $k_{\mathrm{H}} k_{\mathrm{F}} /\left(k_{-\mathrm{F}}+k_{\mathrm{H}}\right)$ shows only a fraction of the isotope effect inherent in $k_{3}$ or $k_{\mathrm{H}}$ and no isotope effect if $k_{3}$ or $k_{\mathrm{H}}>>k_{-\mathrm{F}}$.

$$
\begin{gathered}
E_{1} \mathrm{C} \underset{k_{-\mathrm{F}}}{\stackrel{k_{\mathrm{F}}}{\rightleftharpoons}} E_{2} \mathrm{C} \stackrel{k_{3}}{\longrightarrow} \mathrm{COH} \\
E_{1} \mathrm{OP} \stackrel{k_{-\mathrm{F}}}{\stackrel{k_{\mathrm{F}}}{\rightleftharpoons}} E_{2} \mathrm{OP} \stackrel{k_{\mathrm{H}}}{\longrightarrow} \mathrm{POH}
\end{gathered}
$$

Scheme 4. Extension of Scheme 1 to include an inactive enzyme form ( $E_{1} C$ or $\left.E_{1} \mathrm{OP}\right)$.

We recently investigated the hydrolysis of carbamoylated AChEs for a series of carbamate esters and obtained the solvent $\mathrm{D}_{2} \mathrm{O}$ isotope effects summarized in Figure 6 [2]. The rate constant $k_{3}$ for the smallest carbamoyl group, an $\mathrm{N}$-monomethylcarbamoyl, was $12 \times 10^{-3} \mathrm{~min}^{-1}$, and its isotope effect of 2.8 was consistent with rate-limiting proton transfer and a small value of $C$. However, as the $N$-alkyl groups on carbamoylated AChEs increased in size, the decarbamoylation rate constant $k_{3}$ decreased to about $0.02 \times 10^{-3} \mathrm{~min}^{-1}$ for $\mathrm{N}, \mathrm{N}$-diethylcarbamoylated $\mathrm{AChE}$ and the isotope effect was only slightly above 1 (Figure 6), indicating a high value of $C$. In that report we noted the crystallographic evidence of active site distortion in diethylphosphorylated AChE shown in Figure 2A, and we suggested that a larger size of the carbamoyl group is likely to be an important factor in a shift away from proton transfer in the rate-limiting step for $k_{3}$. It may be useful to explore molecular modeling of the array of conformational variants available in AChEs with large carbamoyl groups to obtain support for this proposal.<smiles>[R]N([R])C(=O)OCC</smiles>

$\begin{array}{cc}\mathrm{R}_{1} & \mathrm{R}_{2} \\ \mathrm{CH}_{3} & \mathrm{H} \\ \mathrm{CH}_{3} & \mathrm{CH}_{3} \\ \mathrm{C}_{2} \mathrm{H}_{5} & \mathrm{CH}_{3} \\ \mathrm{C}_{2} \mathrm{H}_{5} & \mathrm{C}_{2} \mathrm{H}_{5}\end{array}$

$\begin{aligned} & \text { Carbamoyl } \\ & \text { Substituents }\end{aligned} k_{3} \mathrm{H}_{2} \mathrm{O} / k_{3} \mathrm{D}_{2} \mathrm{O}$

$\mathrm{N}$-monomethyl
$\mathrm{N}, \mathrm{N}$-dimethyl
$\mathrm{N}$-ethyl- $\mathrm{N}$-methyl
$\mathrm{N}, \mathrm{N}$-diethyl

$2.8 \pm 0.2$

$2.4 \pm 0.2$

$1.8 \pm 0.2$

$1.1 \pm 0.2$

Figure 6. Solvent $\mathrm{D}_{2} \mathrm{O}$ isotope effects on the AChE decarbamoylation rate constant $k_{3}$ at $25{ }^{\circ} \mathrm{C}[2]$.

We designed the experiments here to examine whether active site distortion in diethylphosphorylated $\mathrm{AChE}$ in fact does result in a shift away from rate-limiting proton transfer in the hydrolysis and oxime reactivation reactions of this $\mathrm{AChE}$ intermediate. For comparison, we included measurements of solvent $\mathrm{D}_{2} \mathrm{O}$ isotope effects for dimethylphosphorylated $\mathrm{AChE}$, an intermediate unlikely to involve active site distortion $[10,12]$. Oxime reactivation, like hydrolysis in Scheme 2, involves attack of a nucleophile on the tetravalent phosphorus to presumably form a pentavalent transition state [24]. This state then decomposes to regenerate active enzyme and an organophosphorylated oxime [7,25], and both the formation and decomposition of this state are likely to involve rate-limiting proton transfer. In the structure in Figure 2B, $50 \mathrm{mM}$ 2-PAM was diffused into the crystal [9]. This structure suggests that 2-PAM stabilizes the active $E_{2} \mathrm{OP}$ species in Scheme 4, perhaps to the exclusion of the distorted $E_{1} \mathrm{OP}$ species, and $k_{\mathrm{R}}$ for diethylphosphorylated AChE in Table 1 is only 5 -fold lower than that for dimethylphosphorylated AChE. These observations suggest that the concentration of $E_{1} \mathrm{OP}$ bound to 2-PAM is negligible and that $k_{\mathrm{R}}$ will reflect the rate-limiting proton transfer inherent when 
both acyl groups migrate to the oxime. The solvent $\mathrm{D}_{2} \mathrm{O}$ isotope effects of 2.0 and 1.7 for the dimethyland diethylphosphorylated $\mathrm{AChE}$ are consistent with this interpretation.

Finally, we examined the rate constants $k_{\mathrm{H}}$ for hydrolysis of both diethylphosphorylated AChE and dimethylphosphorylated $\mathrm{AChE}$ to determine if their solvent $\mathrm{D}_{2} \mathrm{O}$ isotope effects reflect the fact that only diethylphosphorylated AChE appears to form the distorted active conformation in Figure 2A. The values in Table 1 do not support this proposal, as both organophosphorylated species show isotope effects that are close to 2.0. This value, although somewhat low for typical enzyme deacylation, suggests that any distorted conformation $E_{1} \mathrm{OP}$ involving diethylphosphorylated AChE equilibrates relatively rapidly with the active conformation $E_{2} \mathrm{OP}$ and that the commitment to catalysis $\mathrm{C}=k_{\mathrm{H}} / k_{-\mathrm{F}}$ is small. These isotope effects for organophosphorylated AChE hydrolysis are significant because this reaction, of those in Scheme 2, bears the closest resemblance to the hydrolysis of the carbamoylated enzymes in Figure 6. Furthermore, the conclusion above that the commitment to catalysis $\mathrm{C}=k_{3} / k_{-\mathrm{F}}$ is large for $\mathrm{N}, \mathrm{N}$-diethylcarbamoylated $\mathrm{AChE}$ while $\mathrm{C}=k_{\mathrm{H}} / k_{-\mathrm{F}}$ is small for diethylphosphorylated $\mathrm{AChE}$ is difficult to justify. Their respective rate constants, $k_{3}=0.02 \times 10^{-3} \mathrm{~min}^{-1}$ for decarbamoylation and $k_{\mathrm{H}}=0.08 \times 10^{-3} \mathrm{~min}^{-1}$ for dephosphorylation (Table 1 and Figure 6), are too similar to support these opposing conclusions about $\mathrm{C}$ if the same value of $k_{\text {-F }}$ holds for both acylated AChEs.

\section{Materials and Methods}

\subsection{Reagents}

Recombinant hAChE was expressed as a secreted, disulfide-linked dimer in drosophila S2 cells and purified by affinity chromatography as outlined previously [26]. Initial $0.5 \mathrm{~mL}$ fractions were maintained in $5 \mathrm{mM}$ decamethonium bromide (Sigma-Aldrich Chemical Co., St. Louis, MO, USA) at $4{ }^{\circ} \mathrm{C}$. Fractions were dialyzed against $20 \mathrm{mM}$ sodium phosphate and $0.02 \%$ Triton X-100 (pH 7.0) at $4{ }^{\circ} \mathrm{C}$, and 10 - or $20-\mu \mathrm{L}$ aliquots of the dialyzates were frozen at $-20^{\circ} \mathrm{C}$ until use. $O, O$-Diethyl $\mathrm{O}$-(4-nitrophenyl) phosphate (paraoxon) and $\mathrm{O}, \mathrm{O}$-dimethyl $\mathrm{O}$-(4-nitrophenyl) phosphate (paraoxon methyl) were commercial samples from Sigma-Aldrich Chemical Co (St. Louis, MO, USA).

\subsection{Assay of Substrate Hydrolysis}

Hydrolysis rates $v$ for the substrate acetylthiocholine were measured in a coupled Ellman reaction in which thiocholine generated in the presence of the indicated concentration of DTNB was determined by the formation of the thiolate dianion of DTNB at $412 \mathrm{~nm}\left(\Delta \varepsilon_{412 \mathrm{~nm}}=14,150 \mathrm{M}^{-1} \mathrm{~cm}^{-1}\right)$ [27]. Total AChE concentrations $\left(E_{\mathrm{tot}}\right)$ could be calculated assuming 450 units/nmol [28]. One unit of AChE activity corresponds to $1 \mu \mathrm{mol}$ of acetylthiocholine hydrolyzed/min under standard $\mathrm{pH}$-stat assay conditions at $\mathrm{pH} 8$ [28,29]. Our conventional spectrophotometric assay at $412 \mathrm{~nm}$ was conducted in $\mathrm{pH} 7.0$ buffer. With wild type hAChE and $0.5 \mathrm{mM}$ acetylthiocholine, this assay resulted in $4.8 \Delta \mathrm{A}_{412 \mathrm{~nm}} / \mathrm{min}$ with $1 \mathrm{nM} \mathrm{AChE}$ or about $76 \%$ of the $\mathrm{pH}$ stat assay standard, but here $E_{\text {tot }}$ was expressed simply in terms of $\Delta \mathrm{A}_{412} / \mathrm{min}$. The assay mixture here contained final concentrations of acetylthiocholine and DTNB of $1.0 \mathrm{mM}$ and $0.3 \mathrm{mM}$, respectively, in $100 \mathrm{mM}$ sodium phosphate and $0.1 \% \mathrm{BSA}$ at $\mathrm{pH}$ 8.0. Aliquots of $\mathrm{AChE}$ were added to a final volume was $3.0 \mathrm{~mL}$, and the assay was conducted at $25^{\circ} \mathrm{C}$. Absorbance at $412 \mathrm{~nm}$ was recorded with time on a Varian Cary 3A spectrophotometer.

\subsection{Reactions of Organophosphorylated hAChE}

We generated organophosphorylated AChE (EOP in Scheme 1) from either paraoxon (to give diethylphosphorylated AChE) or paraoxon methyl (to give dimethylphosphorylated AChE) as outlined in the legends to Figures 3-5. Experimental traces of organophosphorylated AChE reactions measured with acetylthiocholine activity assays $(v)$ were obtained and the equation for the general solution used to fit these traces to Scheme 2 is given in Equation (2). Data were fitted to Equation (2) by unweighted 
nonlinear regression with SigmaPlot (version 12.0, Systat Software Inc., Chicago, IL, USA). When $k_{\mathrm{r}}>>$ $k_{\mathrm{H}}+k_{\mathrm{A}}+k_{\mathrm{X}}$ and $t=t_{\text {aged }}>>k_{\mathrm{r}}^{-1}$, Equation (2) reduces to Equation (3).

$$
\begin{gathered}
v=\left(E_{\text {tot }} e^{-k_{\mathrm{A}} t_{\text {aged }}}-E_{0}\right) \frac{\left(k_{\mathrm{r}}+k_{\mathrm{H}}\right)\left(e^{-k_{\mathrm{x}} t}-e^{-\left(k_{\mathrm{r}}+k_{\mathrm{H}}+k_{\mathrm{A}}+k_{\mathrm{x}}\right) t}\right)}{\left(k_{\mathrm{r}}+k_{\mathrm{H}}+k_{\mathrm{A}}\right)}+E_{0} e^{-k_{\mathrm{x}} t} \\
v=E_{\mathrm{tot}} e^{-\left(k_{\mathrm{A}}+k_{\mathrm{x}}\right) t_{\mathrm{aged}}}
\end{gathered}
$$

In Equations (2) and (3), $t_{\text {aged }}$ is the time that enzyme and OP were incubated prior to the start of the measured reaction, $t$ is the duration in min of the measured reaction and $E_{0}$ is the initial enzyme concentration $\left(\Delta \mathrm{A}_{412} / \mathrm{min}\right.$ at $\left.t=0\right)$.

Values of the second order reactivation rate constants $k_{\mathrm{r}}$ were obtained at various 2-PAM concentrations that were run in parallel, and these values were analyzed with Equation (4) to obtain the maximal first order reactivation rate constant $k_{\mathrm{R}}$ at saturating concentrations of 2-PAM and the dissociation constant $K_{\mathrm{P}}$ for 2-PAM binding to organophosphorylated AChE.

$$
k_{\mathrm{r}}=\frac{k_{\mathrm{R}}}{1+\frac{K_{\mathrm{P}}}{[2-\mathrm{PAM}]}}
$$

\subsection{Solvent Deuterium Oxide Isotope Effects}

Reactions of organophosphorylated AChE were conducted in $100 \mathrm{mM}$ sodium phosphate and $0.1 \%$ BSA at $\mathrm{pH}$ 8.0. The $\mathrm{pH}$ was the uncorrected value read by the $\mathrm{pH}$ meter for both $\mathrm{H}_{2} \mathrm{O}$ and $\mathrm{D}_{2} \mathrm{O}$ buffers, and the $\mathrm{pH}$ of 8.0 (rather than more typical $\mathrm{pH}$ values of 7.0-7.4 for AChE studies) was selected to minimize enzyme $\mathrm{pK}_{\mathrm{a}}$ differences [3] between $\mathrm{H}_{2} \mathrm{O}$ and $\mathrm{D}_{2} \mathrm{O}$. Organophosphorylated AChE reactions in $\mathrm{D}_{2} \mathrm{O}$ were paired with reactions in $\mathrm{H}_{2} \mathrm{O}$ to maximize precision in comparing rates. While frozen stocks of $\mathrm{AChE}$ were in $\mathrm{H}_{2} \mathrm{O}$, all subsequent dilutions were identical in either $\mathrm{H}_{2} \mathrm{O}$ or $\mathrm{D}_{2} \mathrm{O}$. The percentage $\mathrm{H}_{2} \mathrm{O}$ in an assayed $\mathrm{D}_{2} \mathrm{O}$ aging reaction mixture was $3 \%$, and the maximum percentage in hydrolysis or oxime reactivation mixtures was $1 \%$.

Funding: This research received no external funding.

Conflicts of Interest: The author declares no competing financial interests.

\section{Abbreviations}

AChE: acetylcholinesterase; BSA, bovine serum albumin; hAChE, human acetylcholinesterase; mAChE, mouse acetylcholinesterase; TcAChE, Torpedo californica acetylcholinesterase; DTNB, 5,5'-dithiobis-(2-nitrobenzoic acid); 2-PAM, 2-pyridinealdoxime methiodide.

\section{References}

1. Rosenberry, T.L. Quantitative simulation of endplate currents at neuro-muscular junctions based on the reactions of acetylcholine with acetylcholine receptor and acetylcholinesterase. Biophys. J. 1979, 26, 263-290. [CrossRef]

2. Venkatasubban, K.S.; Johnson, J.L.; Thomas, J.L.; Fauq, A.; Cusack, B.; Rosenberry, T.L. Decarbamoylation of acetylcholinesterases is markedly slowed as carbamoyl groups increase in size. Arch. Biochem. Biophys. 2018, 655, 67-74. [CrossRef] [PubMed]

3. Reiner, E.; Aldridge, W.N. Effect of $\mathrm{pH}$ on inhibition and spontaneous reactivation of acetylcholinesterase treated with esters of phosphorus acids and of carbamic acids. Biochem. J. 1967, 105, 171-179. [CrossRef] [PubMed]

4. Fukuto, T.R. Mechanism of action of organophosphorus and carbamate insecticides. Environ. Health Perspect. 1990, 87, 245-254. [CrossRef]

5. Myers, D.K. Studies on cholinesterase. 10. Return of cholinesterase activity in the rat after inhibition by carbamoyl fluorides. Biochem. J. 1956, 62, 556-563. 
6. Froede, H.C.; Wilson, I.B. Acetylcholinesterase. In The Enzymes, 3rd ed.; Boyer, P.D., Ed.; Academic Press: New York, NY, USA, 1971; pp. 87-114.

7. Wilson, I.B. Acetylcholinesterase. XI. Reversibility of tetraethyl pyrophosphate inhibiton. J. Biol. Chem. 1951, 190, 111-117.

8. Rosenberry, T.L.; Cheung, J. Rate-limiting step in the decarbamoylation of acetylcholinesterases with large carbamoyl groups. Chem. Biol. Interact. 2019, 308, 392-395. [CrossRef]

9. Franklin, M.C.; Rudolph, M.J.; Ginter, C.; Cassidy, M.S.; Cheung, J. Structures of paraoxon-inhibited human acetylcholinesterase reveal perturbations of the acyl loop and the dimer interface. Proteins 2016, 84, 1246-1256. [CrossRef]

10. Hörnberg, A.; Tunemalm, A.K.; Ekström, F. Crystal structures of acetylcholinesterase in complex with organophosphorus compounds suggest that the acyl pocket modulates the aging reaction by precluding the formation of the trigonal bipyramidal transition state. Biochemistry 2007, 46, 4815-4825. [CrossRef]

11. Millard, C.B.; Kryger, G.; Ordentlich, A.; Greenblatt, H.M.; Harel, M.; Raves, M.L.; Segall, Y.; Barak, D.; Shafferman, A.; Silman, I.; et al. Crystal structures of aged phosphonylated acetylcholinesterase: Nerve agent reaction products at the atomic level. Biochemistry 1999, 38, 7032-7039. [CrossRef]

12. Millard, C.B.; Koellner, G.; Ordentlich, A.; Shafferman, A.; Silman, I.; Sussman, J.L. Reaction products of acetylcholinesterase and VX reveal a mobile histidine in the catalytic triad. J. Am. Chem. Soc. 1999, 121, 9883-9884. [CrossRef]

13. Kovalevsky, A.; Blumenthal, D.K.; Cheng, X.; Taylor, P.; Radic, Z. Limitations in current acetylcholinesterase structure-based design of oxime antidotes for organophosphate poisoning. Ann. N. Y. Acad. Sci. 2016, 1378, 41-49. [CrossRef] [PubMed]

14. Michel, H.O.; Hackley, B.E.; Berkowitz, L.; List, G.; Hackley, E.B.; Gillilan, W.; Pankau, M. Ageing and dealkylation of soman (pinacolylmethylphosphonofluoridate)-Inactivated eel cholinesterase. Arch. Biochem. Biophys. 1967, 121, 29-34. [CrossRef]

15. Rosenberry, T.L. Catalysis by acetylcholinesterase. Evidence that the rate-limiting step for acylation with certain substrates precedes general acid-base catalysis. Proc. Natl. Acad. Sci. USA 1975, 72, 3834-3838.

16. Quinn, D.M. Acetylcholinesterase: Enzyme structure, reaction dynamics, and virtual transition states. Chem. Rev. 1987, 87, 955-979. [CrossRef]

17. Worek, F.; Diepold, C.; Eyer, P. Dimethylphosphoryl-inhibited human cholinesterases: Inhibition, reactivation, and aging kinetics. Arch. Toxicol. 1999, 73, 7-14. [CrossRef]

18. Jennings, L.L.; Malecki, M.; Komives, E.A.; Taylor, P. Direct analysis of the kinetic profiles of organophosphate-acetylcholinesterase adducts by MALDI-TOF mass spectrometry. Biochemistry 2003, 42, 11083-11091. [CrossRef]

19. Grosfeld, H.; Barak, D.; Ordentlich, A.; Velan, B.; Shafferman, A. Interactions of oxime reactivators with diethylphosphoryl adducts of human acetylcholinesterase and its mutant derivatives. Mol. Pharmacol. 1996, 50, 639-649.

20. Bender, M.L.; Hamilton, G.A. Kinetic isotope effects of deuterium oxide on several a-chymotrypsin-catalyzed reactions. J. Am. Chem. Soc. 1962, 84, 2570-2576. [CrossRef]

21. Bender, M.L.; Clement, G.E.; Kezdy, F.J.; Heck, H.D.A. The correlation of the pH (pD) dependence and the stepwise mechanism of $\alpha$-chymotrypsin-catalyzed reactions. J. Am. Chem. Soc. 1964, 86, 3680-3690. [CrossRef]

22. Qian, N.; Kovach, I.M. Key active site residues in the inhibition of acetylcholinesterases by soman. FEBS Lett. 1993, 336, 263-266. [CrossRef]

23. Kovach, I.M.; Bennet, A.J. Comparative study of nucleophilic am) enzymic reactions of 2-propyl methylphosphonate derivatives. Phosphorus Sulfur Silicon Relat. Elem. 1990, 51, 51-56. [CrossRef]

24. Wong, L.; Radic, Z.; Bruggemann, R.J.M.; Hosea, N.; Berman, H.A.; Taylor, P. Mechanism of oxime reactivation of acetylcholinesterase analyzed by chirality and mutagenesis. Biochemistry 2000, 39, 5750-5757. [CrossRef] [PubMed]

25. Luo, C.; Saxena, A.; Smith, M.; Garcia, G.; Radic, Z.; Taylor, P.; Doctor, B.P. Phosphoryl oxime inhibition of acetylcholinesterase during oxime reactivation is prevented by edrophonium. Biochemistry 1999, 38,9937-9947. [CrossRef] [PubMed] 
26. Mallender, W.D.; Szegletes, T.; Rosenberry, T.L. Organophosphorylation of acetylcholinesterase in the presence of peripheral site ligands: Distinct effects of propidium and fasciculin. J. Biol. Chem. 1999, 274, 8491-8499. [CrossRef] [PubMed]

27. Johnson, J.L.; Cusack, B.; Davies, M.P.; Fauq, A.; Rosenberry, T.L. Unmasking tandem site interaction in human acetylcholinesterase. Substrate activation with a cationic acetanilide substrate. Biochemistry 2003, 42, 5438-5452. [PubMed]

28. De Ferrari, G.V.; Mallender, W.D.; Inestrosa, N.C.; Rosenberry, T.L. Thioflavin T is a fluorescent probe of the acetylcholinesterase peripheral site that reveals conformational interactions between the peripheral and acylation sites. J. Biol. Chem. 2001, 276, 23282-23287. [CrossRef]

29. Rosenberry, T.L.; Scoggin, D.M. Structure of human erythrocyte acetylcholinesterase. Characterization of intersubunit disulfide bonding and detergent interaction. J. Biol. Chem. 1984, 259, 5643-5652.

Sample Availability: Not available.

(C) 2020 by the author. Licensee MDPI, Basel, Switzerland. This article is an open access article distributed under the terms and conditions of the Creative Commons Attribution (CC BY) license (http://creativecommons.org/licenses/by/4.0/). 